\title{
Psychiatric Bulletin readership survey
}

\author{
Tом FAHY, Trainee Editor, British Journal of Psychiatry
}

The Psychiatric Bulletin was launched in October 1971 as a separate news and notes supplement to the British Journal of Psychiatry. At first, the Bulletin confined itself to publishing College statements, the details of divisional meetings, lists of fellows, and forthcoming events. Over the years, the Bulletin has undergone an ambitious expansion in the range of subjects covered. A special emphasis has been placed on publication of studies of practical clinical management, including the Mental Health Act, audit and training matters. There has also been an increase in papers on cultural, historical and media topics related to psychiatry. Other regular sections include interviews, usually with the elder statesmen of psychiatry, obituaries, conference reports and correspondence. The Bulletin also publishes educational articles, such as those on computing or good practice guidelines.

The expansion in range of articles published in the Bulletin has been parallelled by an impressive rise in the number of published papers. In 1987, 80 papers were published, compared with 241 in 1992. The increase in the number of manuscripts submitted to the Bulletin has led to greater competition for publication space. In 1992, 129 manuscripts were rejected for publication.

The increase in the number and range of articles published in the Bulletin, and the pressure from prospective authors to publish their articles, suggests that the function and aims of the Bulletin should be defined as clearly as possible. Over its 20 years of publication there has been no systematic attempt to consult the Bulletin's readers on their views about the publication. As the first trainee editor appointed to the British Journal of Psychiatry, I was asked to organise such a survey.

\section{The study}

The Bulletin is sent, with the British Journal of Psychiatry, to approximately 8,300 subscribers, the vast majority of whom are based in the British Isles. A random list of 900 fellows, members and inceptors of the Royal College of Psychiatrists, all of whom were in receipt of the Bulletin, was generated by the College Computer Department in November 1992. Each subscriber was sent a four page questionnaire, printed on official College stationery. The questionnaire included three pages of forced choice questions, and one page for free comments. A covering letter asked respondents to return the questionnaire to the College in an enclosed stamped addressed envelope. In an attempt to boost response rates, respondents were informed that their names would be entered in a draw for a Gaskell publication of their choice.

The questionnaires were sent out in mid January 1993. All responses received before the end of April 1993 were included in the study.

\section{Findings}

\section{Number and type of respondents (Table I)}

Four hundred and thirty-seven $(48.6 \%)$ questionnaires were returned to the College within the appointed time. The majority of respondents $(64.3 \%)$ were consultant grade. An additional $24.7 \%$ were senior registrar grade. Less than $4 \%$ were premembership trainees. The majority of the $7.3 \%$ who did not fall into the above categories were retired consultant psychiatrists.

\section{How often did respondents read the Bulletin (Tables I \& II)}

Of respondents, $94.7 \%$ read most or every issue of the Bulletin. Only two respondents never read the Bulletin. More than $97 \%$ of respondents read at least a few selected articles in every issue.

Respondents were then asked how often they read the different main sections of the Bulletin. The sections which were most commonly read were those on innovations in treatment and service provision (sometimes, usually or always read by $95.6 \%$ ), original papers and research reports $(96.1 \%)$, correspondence $(93.4 \%)$, forthcoming events $(91.3 \%)$, audit $(88.8 \%)$, papers on training matters $(88.6 \%)$. The least popular sections were computer articles (28.4\% never read them), psychiatry and the arts $(23.8 \%)$, interviews $(20.8 \%)$, obituaries $(17.6 \%)$, and conference reports $(11 \%)$.

\section{Attitudes to the Bulletin (Table III)}

Respondents were also asked to give their reaction to a selection of 11 statements about the Bulletin. These were an unscientifically selected series of positive and negative statements about the Bulletin which sought views about its future directions. Reactions were also 
TABLE I

\begin{tabular}{lr}
\hline 1. What is your current post? & $\mathrm{n}$ \\
Consultant/Hon. Consultant & $281(64.3)$ \\
Senior Registrar/Lecturer & $108(24.7)$ \\
SHO/Registrar & $16(3.7)$ \\
Other & $32(7.3)$ \\
Total & 437 \\
& \\
2. How regularly do you read the 'Psychiatric Bulletin'? & \\
Every issue & $236(54.0)$ \\
Most issues & $178(40.7)$ \\
Rarely & $19(4.3)$ \\
Never & $2(0.5)$ \\
Missing data & $2(0.5)$ \\
3. How much of the 'Psychiatric Bulletin' do you usually read? & \\
The content list & $11(2.5)$ \\
A few selected articles & $289(66.1)$ \\
The majority of the contents & $125(28.6)$ \\
Virtually the entire contents & $11(2.5)$ \\
Missing data & $1(0.2)$ \\
4ave you published any papers/reports or letters in the Psychiatric Bulletin'? & \\
Yes & $148(33.9)$ \\
No & $286(65.4)$ \\
Missing data & $3(0.7)$ \\
\hline
\end{tabular}

TABLE II

How often do you read the following sections of the 'Psychiatric Bulletin'?

\begin{tabular}{lccc}
\hline & $\begin{array}{c}\text { Never } \\
\%\end{array}$ & $\begin{array}{c}\text { Sometimes } \\
\%\end{array}$ & $\begin{array}{c}\text { Usually/ } \\
\text { Always } \\
\%\end{array}$ \\
\hline Interviews & 20.8 & 59.5 & 16.9 \\
Audit in Practice & 8.9 & 45.3 & 43.5 \\
Papers on Training Matters/Trainees Forum & 9.6 & 48.3 & 40.3 \\
Innovations in treatment/service provision & 2.7 & 33.6 & 62.0 \\
Psychiatry and the Arts, Opera etc & 23.8 & 50.8 & 22.4 \\
Conference reports & 11.0 & 61.3 & 24.6 \\
Computer articles & 28.4 & 46.0 & 22.7 \\
Obituaries & 17.6 & 49.0 & 31.6 \\
Original papers/Research reports & 1.4 & 42.8 & 53.3 \\
Book/Video reviews & 9.2 & 50.3 & 38.2 \\
Correspondence & 4.8 & 39.4 & 54.0 \\
Forthcoming events/Conferences & 6.4 & 38.7 & 52.6 \\
\hline
\end{tabular}

sought to critical and supportive comments which had been raised in editorial meetings, and which might reflect the different ways in which the Bulletin could develop.

The great majority of respondents agreed with the statement that the Bulletin provides an interesting and varied selection of articles $(82.8 \%)$, and that it is a useful forum for research of everyday use to clinical psychiatrists (60.6\%). A majority (52.9\%) disagreed with the statement that the quality of original articles is low, whereas only $12.6 \%$ of respondents agreed with this statement; $52.2 \%$ agreed that the Bulletin was not in need of substantial review of change, whereas $11 \%$ disagreed with this statement.

With regard to the future direction of the Bulletin, strong support was expressed for the statement that 
TABLE III

Please give your reaction to the following statements about the 'Psychiatric Bulletin' by ticking the appropriate box

\begin{tabular}{lrrr}
\hline & $\begin{array}{c}\text { Agree } \\
\%\end{array}$ & $\begin{array}{c}\text { Uncertain } \\
\%\end{array}$ & $\begin{array}{c}\text { Disagree } \\
\%\end{array}$ \\
\hline It provides an interesting and varied selection of articles & 82.8 & 13.3 & 3.0 \\
The quality of most original papers and articles is improving & 49.0 & 44.9 & 5.0 \\
The conference reports are useful & 46.2 & 41.6 & 10.8 \\
The proportion devoted to College business should be greater & 24.9 & 40.0 & 34.3 \\
The quality of original papers articles is generally low & 12.6 & 33.2 & 52.9 \\
It is a useful forum for research of every day use to clinical psychiatrists & 60.6 & 23.1 & 14.9 \\
It should increasingly publish articles selected for scientific quality & 20.8 & 29.7 & 48.5 \\
More space should be devoted to research by junior doctors & 38.7 & 32.5 & 28.4 \\
There should be more emphasis on clinical/service/training issues & 62.5 & 28.1 & 8.7 \\
It is not in need of substantial review or change & 52.2 & 35.5 & 11.0 \\
Regular readership surveys should be undertaken to review the need for future change & 64.5 & 24.7 & 8.9 \\
\hline
\end{tabular}

there should be more emphasis on clinical, service and training issues $(62.5 \%)$, whereas only $8.7 \%$ disagreed with this statement. The majority of respondents did not agree with the statement that the Bulletin should increasingly publish articles selected for scientific quality $(48.5 \%$ disagreed, and $29.7 \%$ were uncertain), whereas only $20.8 \%$ agreed with this statement. Views were divided on the suggestion that there should be more emphasis on College business and research by junior doctors. A majority agreed that regular readership surveys should be undertaken.

\section{Views of consultants and junior stafi}

The responses of consultants and senior lecturers were compared with those of junior doctors. Consultants were significantly more likely to read interviews, obituaries and reviews. Junior doctors were more likely to read articles on training and computers. Consultants were more likely to agree with the statements that the Bulletin provides an interesting and varied selection of articles, and that the quality was improving. Junior doctors were more likely to agree with statements that the quality of original papers and articles is generally low, and that more space should be devoted to research by junior doctors.

\section{Comments and suggestions}

One hundred and eighty-six (43\%) respondents accepted the invitation to add their comments on the content, style and future direction of the Psychiatric Bulletin. The commonest suggestion was that the Bulletin should continue to publish articles on practical issues of service delivery, audit management issues and NHS changes $(n=38)$. A large number also suggested that the Bulletin should continue to provide a forum for articles on training and College information $(n=27)$. A large number of respondents urged that the Bulletin should not attempt to become "too scientific", or to resemble the British Journal of Psychiatry $(\mathrm{n}=33)$. Twenty respondents emphasised that the Psychiatric Bulletin was of more interest and clinical relevance to them than the British Journal of Psychiatry. Sixteen respondents said that the Bulletin was doing a good job and did not require any significant changes. Smaller numbers suggested that the design and layout of the Bulletin was very dull, that interviews were too long, that educational updates would be a useful feature, that the subspecialities were underrepresented and that research papers should be peer reviewed.

\section{Comment}

The readership survey achieved a relatively good response rate of $48.6 \%$. Consultants were overrepresented, possibly reflecting greater interest in the Bulletin and difficulty contacting more mobile junior staff. However, the 437 respondents constitute more than $5 \%$ of the entire readership of the Bulletin, and it is likely that the views expressed are a reasonable reflection of the readership at large.

In general terms, the survey suggests that the great majority of readers have a favourable opinion of the Bulletin and maintain a high level of interest in the publication. At least $95 \%$ of respondents read most of every issue, and $97 \%$ read at least a few articles in each issue. The most popular sections are those dealing with practical service related issues, including innovations in treatment, service provision and audit. None of the sections of the Bulletin were very unpopular, but articles on the arts, interviews and obituaries had the smallest number of regular readers.

The general attitude of most respondents towards the Bulletin was quite complimentary, with $80 \%$ 
agreeing that it was doing a good job, and only $11 \%$ agreeing with the statement that it was in need of substantial review. However, a number of important concerns emerged from the survey results. Most readers see the Bulletin's main role as the provision of information relevant to the day to day practice of psychiatry, and many suggested that there should be increasing emphasis on management issues and the NHS reforms. The Bulletin should continue to report on training matters and College affairs. There was a strong undercurrent of opinion that the British Journal of Psychiatry did not cater for the practical needs of psychiatrists. This could be explored further in a survey of Journal readers.

The survey also established that readers would like the British Journal of Psychiatry and the Psychiatric Bulletin to maintain separate and distinct roles. The Bulletin should not try to emulate the Journal by becoming too scientific. However, some scientific papers relating to service and clinical matters were desirable, and these should be reviewed with the same rigour as publications in the Journal.

Readers acknowledge that the Bulletin has improved in quality and has established an important role and clear identity in commenting on the day to day practical and clinical duties of psychiatrists. The Bulletin should continue to address these needs, and attempt to provide an up to date information source on clinical, management and political developments affecting psychiatry. There was no popular support for the Bulletin going beyond these objectives and developing a role as a scientific journal. Many readers called for lively, up to date and occasionally humorous contributions and debates.
The rather dull and old fashioned layout of the publication would need to be radically changed if these objectives are to be met.

\section{Conclusions}

1. The Psychiatric Bulletin is doing a good job. It is widely read and readers' satisfaction ratings are high.

2. Readers see the central role of the Bulletin as a forum for reporting of service developments, audit, training issues and College business.

3. Readers would like to see more articles on management and health service changes.

4. A clear demarcation in function should exist between the British Journal of Psychiatry and the Psychiatric Bulletin.

5. The Psychiatric Bulletin should not become a second class version of the British Journal of Psychiatry.

6. Scientific reports should be of practical clinical relevance and should undergo peer review.

7. Interviews are too long. There should be more interviews with contemporary figures.

8. Some articles on the arts and psychiatry are not well received. There may be a case for more vigorous editing of this type of material.

9. There would appear to be a strong demand for articles which give updates on clinically relevant topics from the current literature.

10. The subspecialities are under-represented.

11. The style of the Psychiatric Bulletin is boring and in need of a major overhaul. 